\title{
Validity of transcutaneous oxygen/carbon dioxide pressure measurement in the monitoring of mechanical ventilation in stable chronic respiratory failure
}

\author{
V. Rosner*, B. Hannhart**, F. Chabot*, J.M. Polu*
}

\begin{abstract}
Validity of transcutaneous oxygen/carbon dioxide pressure measurement in the monitoring of mechanical ventilation in stable chronic respiratory failure. V. Rosner, B. Hannhart, F. Chabot, J.M. Polu. (C)ERS Journals Ltd 1999.

ABSTRACT: The accuracy and precision of transcutaneous pressure measurements of oxygen $\left(\mathrm{Ptc}, \mathrm{O}_{2}\right)$ and carbon dioxide $\left(\mathrm{Ptc}, \mathrm{CO}_{2}\right)$ in the monitoring of nocturnal assisted ventilation in adult patients were evaluated.

Transcutaneous measurements obtained with two analysers, Radiometer TINATCM3 (R) and Kontron MicroGas-7650 (K), were compared with arterial blood gases analysed in blood samples withdrawn simultaneously in 10 patients. Sensors were heated to $43^{\circ} \mathrm{C}$. Measurements of trascutaneous blood gases and arterial blood gases were collected six times at 1-h intervals.

The data obtained with both instruments were similar and did not significantly change over the $5 \mathrm{~h}$ test period. Measurement of $P_{t c}, O_{2}$ underestimated arterial oxygen tension $\left(\mathrm{Pa}_{2} \mathrm{O}_{2}\right)$ and this underestimation increased with the level of $\mathrm{Pa}_{2}, \mathrm{O}_{2}(\mathrm{p}<0.01)$. Measurements of $P \mathrm{tc}, \mathrm{CO}_{2}$ overestimated arterial carbon dioxide tension $\left(\mathrm{Pa}_{2}, \mathrm{CO}_{2}\right)$ and this overestimation increased with the level of $\mathrm{Pa}_{1}, \mathrm{CO}_{2}(\mathrm{p}<0.05)$. These errors suggested an instrumental bias. Mathematical correction of this bias neutralized the error in accuracy and improved the precision (SD of the differences transcutaneous blood gases - arterial blood gases). An additional correction, suppressing the between-subject scattering, improved the actual precision: precision was reduced from 1.9 to $0.8 \mathrm{kPa}$ (14.4 to $5.7 \mathrm{mmHg})(\mathrm{R})$ and from 1.7 to $0.5 \mathrm{kPa}(13.1$ to $3.7 \mathrm{mmHg})(\mathrm{K})$ for oxygen, and from $1.0 \mathrm{kPa}(7.8 \mathrm{mmHg})(\mathrm{R})$ and $0.7 \mathrm{kPa}(5.6 \mathrm{mmHg})(\mathrm{K})$ to $0.4 \mathrm{kPa}(3.2 \mathrm{mmHg})$ for carbon dioxide ( $R$ and $K)$.

In conclusion, with these two successive corrections, transcutaneous oxygen and carbon dioxide provide a reliable estimation of blood gases to monitor nocturnal ventilation in adults with chronic respiratory failure.
\end{abstract}

Eur Respir J 1999; 13: 1044-1047.

\begin{abstract}
*Service des Maladies Respiratoires et Réanimation Respiratoire, CHU de Nancy, France. **U 14 INSERM de Physiopathologie Respiratoire, Vandoeuvre-lès-Nancy, France.
\end{abstract}

Correspondence: F. Chabot

Service des Maladies Respiratoires et Réanimation Respiratoire

CHU de Nancy

54500 Vandoeuvre-lès-Nancy

France

Fax: 33383154023

Keywords: Blood gases

carbon dioxide

chronic respiratory failure

metrology

nocturnal assisted ventilation

oxygen

Received: June 241998

Accepted after revision January 111999
Nocturnal assisted positive pressure ventilation is effective in the treatment of severe hypercapnic chronic respiratory disease. Its primary objective is to reduce hypercapnia and its efficacy is usually judged by arterial blood gas determination (arterial oxygen tension $\left(\mathrm{Pa}_{\mathrm{a}} \mathrm{O}_{2}\right)$ and arterial carbon dioxide tension $\left.\left(\mathrm{Pa}_{\mathrm{a}} \mathrm{CO}_{2}\right)\right)$. Transcutaneous oxygen $\left(P \mathrm{tc}, \mathrm{O}_{2}\right)$ and carbon dioxide $\left(P \mathrm{tc}, \mathrm{CO}_{2}\right)$ tensions reflect partial pressures of gases in arterial blood. Usually, a combined oxygen $\left(\mathrm{PO}_{2}\right)$ /carbon dioxide $\left(\mathrm{PCO}_{2}\right)$ tension skin probe equipped with Clark and Stow-Severinghaus electrodes is used to measure $P \mathrm{tc}, \mathrm{O}_{2}$ and $P \mathrm{tc}, \mathrm{CO}_{2}$ after "arteriolization" of the skin by warming to a temperature between $41^{\circ} \mathrm{C}$ and $45^{\circ} \mathrm{C}$. In the newborn, because of skin thinness, transcutaneous values of oxygen and carbon dioxide approach the pressures in arterial blood [1]. The main advantage is the real-time estimation over prolonged periods of time without necessity of blood sampling.

The purpose of this study was to determine the accuracy and precision of this method in the monitoring of nocturnal assisted ventilation in adult patients with stable severe chronic respiratory failure. Measurements of $P \mathrm{tc}, \mathrm{O}_{2}$ and $P \mathrm{tc}, \mathrm{CO}_{2}$ obtained hourly with two different devices were compared with the values of $\mathrm{Pa}, \mathrm{O}_{2}$ and $\mathrm{Pa}, \mathrm{CO}_{2}$ measured simultaneously in arterial blood. The correction of instrumental and individual sources of dispersion should allow estimation of the actual precision of the measurements obtained by this method.

\section{Materials and methods}

Ten patients (seven males and three females), mean age of 64 yrs (range 53-73 yrs), were included in this study. None of the subjects were obese (body mass index between 22 and $30 \mathrm{~kg} \cdot \mathrm{m}^{-2}$ ). The patients suffered from severe chronic respiratory failure due to chronic obstructive pulmonary disease $(n=5)$, kyphoscoliosis $(n=4)$ and sequelae of tuberculosis $(n=1)$. They all benefited from nocturnal assisted ventilation and, in six cases, long-term supplemental oxygen. None of the patients had a recent history of acute respiratory failure and all were haemodynamically stable. They were hospitalized either for initiation or routine yearly control of their mechanical nocturnal ventilation via a nasal mask $(\mathrm{n}=9)$ or tracheostomy cannula 
$(n=1)$. They were ventilated, as needed, with supplemental oxygen at a flow rate of $1-3 \mathrm{~L} \cdot \mathrm{min}^{-1}$. Each subject gave their informed consent following a detailed presentation of study objectives and protocol. This study was approved by the local ethics committee. In each patient, an indwelling catheter was inserted in the radial artery. Blood gas determinations were performed using a Radiometer ABL 520 device (Copenhagen, Denmark). Measurements of $P \mathrm{tc}, \mathrm{O}_{2}$ and $P \mathrm{tc}, \mathrm{CO}_{2}$ were recorded simultaneously using two monitors equipped with heated dual $\mathrm{PO}_{2} / \mathrm{PCO}_{2}$ electrodes, the Radiometer TINA TCM3 with an E5280 probe (R), and the Kontron Instruments MicroGas 7650 (K; Basle, Switzerland). Both monitors were calibrated according to the manufacturer's instructions. In vivo calibration using a reference arterial blood sample was not performed.

\section{Study protocol}

Assisted ventilation was initiated at 22:00 h. Probes were randomly placed on the skin of either the right or left subclavicular region of the bed-resting patient. The probes were heated to $43^{\circ} \mathrm{C}$ and maintained on the skin for $<6 \mathrm{~h}$ to avoid burning [2]. After $20 \mathrm{~min}, P_{\mathrm{tc}, \mathrm{O}_{2}}$ and $P_{\mathrm{tc}, \mathrm{CO}_{2} \text { values }}$ were recorded, and a $3 \mathrm{~mL}$ sample of arterial blood withdrawn simultaneously for blood gas determination. The latter was taken as a reference value. Transcutaneous pressure measurements as well as the simultaneous arterial blood gas sampling were then repeated fivetimes at hourly intervals.

\section{Data analysis}

Comparison between transcutaneous pressure and arterial blood gas measurements. The difference between transcutaneous blood gas tension $\left(P \mathrm{tc}, \mathrm{O}_{2} / \mathrm{CO}_{2}\right)$ and arterial blood gas tensions $\left(P \mathrm{a}, \mathrm{O}_{2} / \mathrm{CO}_{2}\right)$ was expressed as $\Delta\left(P \mathrm{tc}, \mathrm{O}_{2} / \mathrm{CO}_{2}-P \mathrm{a}, \mathrm{O}_{2} / \mathrm{CO}_{2}\right)$. The mean of the 60 differences represents the accuracy of $P \mathrm{tc}, \mathrm{O}_{2} / \mathrm{CO}_{2}$, as stated in the literature. The standard deviation of the distribution of these differences represents the precision of the measurements. The relationship between the $\Delta\left(P \mathrm{tc}, \mathrm{O}_{2} / \mathrm{CO}_{2}-\right.$ $\left.P \mathrm{a}, \mathrm{O}_{2} / \mathrm{CO}_{2}\right)$ and the magnitude of the corresponding $P \mathrm{a}, \mathrm{O}_{2} / \mathrm{CO}_{2}$ taken as the reference value was analysed by linear regression using the least-square method.

Variability over time. To detect any systematic and progressive change in the relationship between $P \mathrm{tc}, \mathrm{O}_{2} / \mathrm{CO}_{2}$ and $\mathrm{Pa}, \mathrm{O}_{2} / \mathrm{CO}_{2}$ over the $5 \mathrm{~h}$ study period, the six differences in each patient were tested as a function of time by analysis of variance for repeated measurements (ANOVA and Scheffe's test) [3].

\section{Results}

The transcutaneous probes were well tolerated and no burns occurred over the $5 \mathrm{~h}$ study period. The handling of both devices was simple. With the exception of the ease of automatic calibration for the Kontron monitor, there was no notable difference in the use of the devices.
Comparison between transcutaneous pressure and arterial blood measures

Accuracy and precision of $P \mathrm{tc}, \mathrm{O}_{2} / \mathrm{CO}_{2}$ are listed in table 1. For oxygen, the mean difference was negative, reflecting an overall underestimation of $\mathrm{Pa}, \mathrm{O}_{2}$ by transcutaneous measurement. On the contrary, it was positive for $P \mathrm{tc}, \mathrm{CO}_{2}$, and corresponded to an overall overestimation of $P \mathrm{a}, \mathrm{CO}_{2}$. The results obtained with the two monitors did not differ significantly.

The overall relationship between the $\Delta\left(P \mathrm{tc}, \mathrm{O}_{2} / \mathrm{CO}_{2}-P_{\mathrm{a}}, \mathrm{O}_{2} /\right.$ $\left.\mathrm{CO}_{2}\right)$ and $P \mathrm{a}, \mathrm{O}_{2} / \mathrm{CO}_{2}$ are plotted in figure 1 for oxygen and in figure 2 for carbon dioxide. In the case of oxygen, underestimation increased with $\mathrm{Pa}_{\mathrm{a}} \mathrm{O}_{2}$ levels $(\mathrm{p}<0.01)$, with a large scattering from -6.9 to $+1.9 \mathrm{kPa}(-52$ to +14 $\mathrm{mmHg}$ ) for $\mathrm{R}$, and from -6.9 to $+0.9 \mathrm{kPa}(-52$ to $+7 \mathrm{mmHg})$ for $\mathrm{K}$. For carbon dioxide, overestimation was slight during normocapnia $\left(\mathrm{Pa}_{\mathrm{a}} \mathrm{CO}_{2}<5.9 \mathrm{kPa}(<44 \mathrm{mmHg})\right)$ with extreme values ranging $-0.7-+2.0 \mathrm{kPa}(-5-+15 \mathrm{mmHg})$ for $\mathrm{R}$ and $-1.2-+1.5 \mathrm{kPa}(-9-+11 \mathrm{mmHg})$ for $\mathrm{K}$, but increased significantly $(\mathrm{p}<0.05)$ in hypercapnia, reaching $2.7 \mathrm{kPa}(20 \mathrm{mmHg})$ with both monitors when $\mathrm{Pa}_{\mathrm{a}} \mathrm{CO}_{2}$ exceeded $6.7 \mathrm{kPa}(50 \mathrm{mmHg})$. There was no significant difference between the two monitors. For each of the instruments, and both gases, the slopes of the individual least-square lines between the $\Delta\left(P \mathrm{tc}, \mathrm{O}_{2} / \mathrm{CO}_{2}-P \mathrm{a}, \mathrm{O}_{2} / \mathrm{CO}_{2}\right)$ and $\mathrm{Pa}, \mathrm{O}_{2} / \mathrm{CO}_{2}$ were similar for all subjects (covariance analysis), showing a systematical bias presumably due to the instrument.

\section{Variability as a function of time}

As confirmed by the variance analysis, the mean differences $\Delta\left(P \mathrm{tc}, \mathrm{O}_{2} / \mathrm{CO}_{2}-\mathrm{Pa}, \mathrm{O}_{2} / \mathrm{CO}_{2}\right)$ remained constant over the $5 \mathrm{~h}$ study period. The two monitors did not differ significantly.

\section{Discussion}

Several studies have compared transcutaneous tensions and arterial blood gas determinations for carbon dioxide alone [4-7], or associated with oxygen $[8,9]$ in children and in adults. The underestimation of $\mathrm{Pa}_{\mathrm{a}} \mathrm{O}_{2}$ by the transcutaneous determination is attributed to oxygen consumption by superficial tissues and the overestimation of

Table 1. - Accuracy and precision of transcutaneous versus arterial blood gas determinations, for oxygen and carbon dioxide in 60 measurements: effects of the successive corrections of instrumental bias and between-subject variability

\begin{tabular}{|c|c|c|c|c|}
\hline & \multicolumn{2}{|c|}{$\Delta P \mathrm{tc}, \mathrm{O}_{2}-P \mathrm{a}, \mathrm{O}_{2}$} & \multicolumn{2}{|c|}{$\Delta P \mathrm{tc}, \mathrm{CO}_{2}-P \mathrm{a}, \mathrm{CO}_{2}$} \\
\hline & $\mathrm{R}$ & K & $\mathrm{R}$ & K \\
\hline Accuracy & -10.9 & -15.1 & 8.1 & 7.1 \\
\hline Initial precision & 14.4 & 13.1 & 7.8 & 5.6 \\
\hline $\begin{array}{l}\text { Precision after correction } \\
\text { of instrumental bias }\end{array}$ & 8.8 & 8.0 & 5.8 & 4.6 \\
\hline $\begin{array}{l}\text { Precision after suppres- } \\
\text { sion of between- } \\
\text { subject variability }\end{array}$ & 5.7 & 3.7 & 3.2 & 3.2 \\
\hline
\end{tabular}

Results are expressed in $\mathrm{mmHg}$. $P \mathrm{tc}_{\mathrm{O}} \mathrm{O}_{2}$ : transcutaneous oxygen tension; $\mathrm{Pa}, \mathrm{O}_{2}$ : arterial oxygen tension; $P \mathrm{tc}, \mathrm{CO}_{2}$ : transcutaneous carbon dioxide tension; $\mathrm{Pa}_{\mathrm{a}} \mathrm{CO}_{2}$ : arterial carbon dioxide tension; $\mathrm{R}$ : radiometer; K: kontron. $1 \mathrm{mmHg}=0.133 \mathrm{kPa}$. 

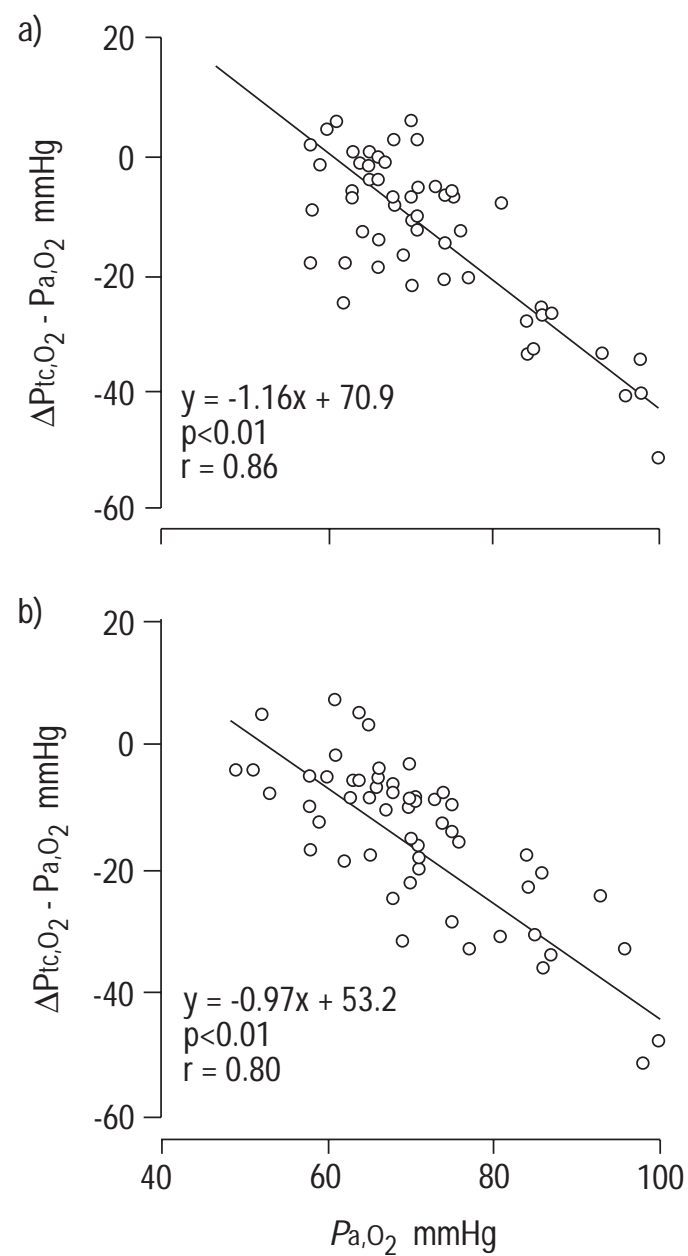

Fig. 1. - Differences between transcutaneous oxygen tension $\left(P \mathrm{tc}, \mathrm{O}_{2}\right)$ and arterial oxygen tension $\left(\mathrm{Pa}_{\mathrm{a}} \mathrm{O}_{2}\right),\left(\Delta\left(\mathrm{Ptc}_{\mathrm{t}} \mathrm{O}_{2}-\mathrm{Pa}_{\mathrm{a}} \mathrm{O}_{2}\right)\right)$, related to $\mathrm{Pa}, \mathrm{O}_{2}$ in 10 subjects (six measurements for each subject, i.e. a total of 60 measurements) for: a) Radiometer TINA TCM3; and b) Kontron Instruments MicroGas analyser. $1 \mathrm{mmHg}=0.133 \mathrm{kPa}$.

$\mathrm{Pa}_{\mathrm{a}, \mathrm{CO}_{2}}$ to tissue metabolic production. Estimation of $\mathrm{Pa}, \mathrm{O}_{2} / \mathrm{CO}_{2}$ by $\mathrm{Ptc}, \mathrm{O}_{2} / \mathrm{CO}_{2}$ is better for carbon dioxide than for oxygen because of the better diffusion of the former [2]. In other studies, trancutaneous and arterial measurements were better correlated than those reported here [49]. These results could probably, at least partially, be explained by the younger age of their studied population (neonates and children [8]) and by the higher probe temperature (44 versus $\left.43^{\circ} \mathrm{C}[4,8,9]\right)$. More recently, JANSSENS et al. [7], with a probe heated to $43.5^{\circ} \mathrm{C}$, found, in adults, an accuracy of $P \mathrm{tc}, \mathrm{CO}_{2}$ of $0.1 \mathrm{kPa}(0.75 \mathrm{mmHg})$ with a precision of $0.3 \mathrm{kPa}(2.6 \mathrm{mmHg})$. The delay in which $P \mathrm{tc}, \mathrm{O}_{2}$ and $P \mathrm{tc}, \mathrm{CO}_{2}$ respond to actual arterial changes must also be taken into account [9]. However, in the current patients in steady conditions, the variations in blood gas levels were small and slow, and the delay probably only played a small role.

In the present study, the more $\mathrm{Pa}_{\mathrm{a}} \mathrm{O}_{2}$ increased, the greater the magnitude of underestimation by $\mathrm{Ptc}, \mathrm{O}_{2}$. Consequently, an improvement in blood gases could potentially be overlooked. As previously reported [8], the mean value of $\Delta\left(P \mathrm{tc}, \mathrm{O}_{2}-P \mathrm{a}, \mathrm{O}_{2}\right)$ clearly increased for $P \mathrm{a}, \mathrm{O}_{2}$ values $>10.6 \mathrm{kPa}(>80 \mathrm{mmHg})$. The increase in the over-
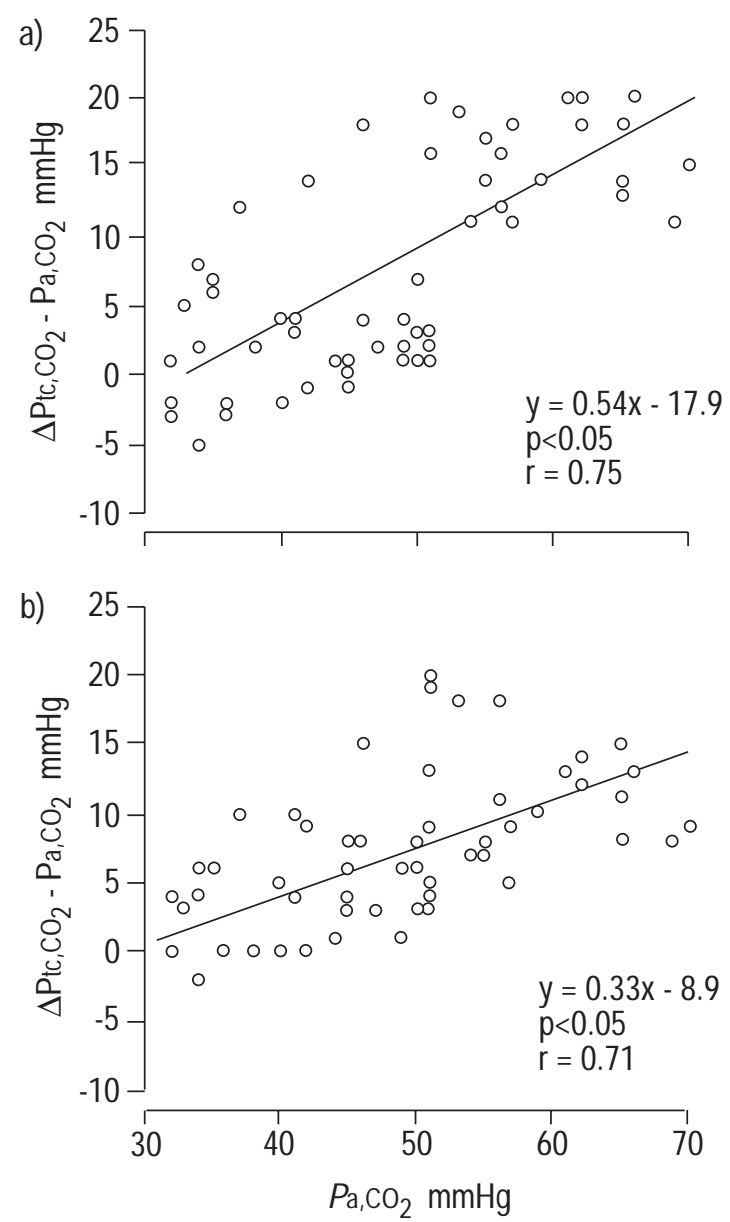

Fig. 2. - Differences between transcutaneous carbon dioxide tension $\left(P \mathrm{tc}, \mathrm{CO}_{2}\right)$ and arterial carbon dioxide tension $\left(P_{\mathrm{a}}, \mathrm{CO}_{2}\right),\left(\Delta\left(P \mathrm{tc}, \mathrm{CO}_{2}-\right.\right.$ $\left.P \mathrm{a}, \mathrm{CO}_{2}\right)$ ), related to $P_{\mathrm{a}}, \mathrm{CO}_{2}$ in 10 subjects (six measurements for each subject i.e. a total of 60 measurements) for: a) Radiometer TINA TCM3; and b) Kontron Instruments MicroGas analyser. $(1 \mathrm{mmHg}=0.133 \mathrm{kPa}$.)

estimation in $P \mathrm{a}_{\mathrm{a}} \mathrm{CO}_{2}$ by transcutaneous measurement when $P a, \mathrm{CO}_{2}$ surpassed $6.7 \mathrm{kPa}(50 \mathrm{mmHg})$ as found in this study was not observed by SANDERS et al. [6], but noticed by JANSSENS et al. [7]. This discrepancy can be explained by the difference in the range of observed $\mathrm{PCO}_{2}$.

In this study, arterial blood gas and transcutaneous blood gas measurements were repeated over $5 \mathrm{~h}$. In accordance with JANSSENS et al. [7], this study found no evidence of an influence of time on the magnitude of the differences, in spite of the slight risk of electrode signal drift estimated at $0.13 \mathrm{kPa} \cdot \mathrm{h}^{-1}\left(1 \mathrm{mmHg} \cdot \mathrm{h}^{-1}\right)$ by the manufacturer.

From these results, $P \mathrm{a}, \mathrm{O}_{2}$ and $P \mathrm{a}, \mathrm{CO}_{2}$ do not seem to be adequately reflected by transcutaneous tensions. However, the observed differences could presumably result from uncertainty owing to either instrumental or individual source linked to between-subject and within-subject variability. These two sources of error have to be eliminated in order to approach the real precision of blood gas estimation.

\section{Instrumental source of uncertainty}

The individual correlations between $\Delta\left(P \mathrm{tc}, \mathrm{O}_{2} / \mathrm{CO}_{2}-\mathrm{Pa}, \mathrm{O}_{2} /\right.$ $\mathrm{CO}_{2}$ ) and $\mathrm{Pa}, \mathrm{O}_{2} / \mathrm{CO}_{2}$ present a parallelism in their slope, 
showing a systematic bias. Accuracy and precision of both monitors, for both gases, could be improved as shown in table 1 , if the instrumental bias was rectified for the data by applying a corrective factor corresponding to the linear regression (figs. 1 and 2). Such a correction also improves the precision of $P \mathrm{tc}, \mathrm{O}_{2}$ and $\mathrm{Ptc}_{\mathrm{tc}}, \mathrm{CO}_{2}$ by $\sim 39$ and $22 \%$, respectively. Consequently, these results became closer to those reported elsewhere [4, 5, 7-9].

\section{Individual scoring of uncertainty}

Once instrumental bias calculated from all 60 measurements has been corrected for, the residual scattering of the data which affects precision is the result of both betweensubject and within-subject variability. Assuming that the source of this between-subject dispersion remains stable in one given subject over the six measurements, it can be eliminated by expressing individual data as a change in $P \mathrm{tc}, \mathrm{O}_{2} / \mathrm{CO}_{2}$ from an individual baseline value instead of absolute values. So, each individual $P \mathrm{tc}, \mathrm{O}_{2} / \mathrm{CO}_{2}$ can be subtracted from the mean of the six measures. Such a correction of the between-subject variability results in an additional improvement in the precision of $P \mathrm{tc}, \mathrm{O}_{2}$ and $\mathrm{Ptc}_{\mathrm{tc}} \mathrm{CO}_{2}$ (table 1). This type of variability can be reduced by an individual in vivo calibration, but this needs an initial arterial blood gas sampling.

Finally, after correction, the residual within-subject dispersion represents the true precision of transcutaneous blood gas measurements which could be expected in a given patient (table 1). Its source remains uncertain. However, the residual lack of precision could be further optimized by repeated measurements, preferably under the same conditions, with calculation of a mean value.

In summary, the results obtained by both the Radiometer and Kontron monitors of comparable technology were similar and did not vary with time. The lack of accuracy appeared to be largely owing to instrumental bias which underestimated high oxygen tensions and overestimated high carbon dioxide tensions. This bias could benefit from an improvement in the software. Accuracy and precision could, therefore, be largely improved. Moreover, taking the between-subject variability into account allows a better estimation of the actual precision. The final precision is compatible with the use of these monitors in the noninvasive monitoring of nocturnal assisted ventilation in severe chronic respiratory failure in adults.

\footnotetext{
Acknowledgements. The authors thank W. Canada for translation of this manuscript, F. Schrijen for proof reading the manuscript and B. Clement for typing the manuscript and M.C. Rohrer for technical assistance.
}

\section{References}

1. Hoppenbrouwers T, Hodgman JE, Arakawa K, Durand M, Cabal LA. Transcutaneous oxygen and carbon dioxide during the first half year of life in premature and normal term infants. Pediatr Res 1992; 31: 73-79.

2. Clark JS, Votteri B, Ariagno RL, et al. Noninvasive assessment of blood gases. Am Rev Respir Dis 1992; 145: 220-232.

3. Winer BJ, ed. Statistical Principles in Experimental Design. 2nd Edn. New York, McGraw-Hill, 1971.

4. Phan CQ, Tremper KK, Lee SE, Barker SJ. Noninvasive monitoring of carbon dioxide: a comparison of the partial pressure of transcutaneous and end-tidal carbon dioxide with the partial pressure of arterial carbon dioxide. J Clin Monit 1987; 3: 149-154.

5. Reid CW, Martineau RJ, Miller DR, Hull KA, Baines J, Sullivan PJ. A comparison of transcutaneous end-tidal and arterial measurements of carbon dioxide during general anaesthesia. Can J Anaesth 1992; 39: 31-36.

6. Sanders MH, Kern NB, Constantino JP, et al. Accuracy of end-tidal and transcutaneous $\mathrm{PCO}_{2}$ monitoring during sleep. Chest 1994; 106: 472-483.

7. Janssens JP, Howarth-Frey C, Chevrolet JC, Abajo B, Rochat T. Transcutaneous $\mathrm{PCO}_{2}$ to monitor noninvasive mechanical ventilation in adults. Chest 1998; 113: 768773.

8. Palmisano BW, Severinghaus JW. Transcutaneous $\mathrm{PCO}_{2}$ and $\mathrm{PO}_{2}$ : a multicenter study of accuracy. J Clin Monit 1990; 6: 189-195.

9. Kesten S, Chapman KR, Rebuck AS. Response characteristics of a dual transcutaneous oxygen/carbon dioxide monitoring system. Chest 1991; 99: 1211-1215. 